\title{
Analysis of calcareous sand particle shape using fourier descriptor analysis
}

\author{
Lamia Touiti ${ }^{*}$ D , Taesik Kim² and Young-Hoon Jung ${ }^{3}$
}

\author{
*Correspondence: \\ touiti.l@gmail.com \\ ${ }^{1}$ LGC Civil Engineering \\ Laboratory - Ecole Nationale \\ d'Ingénieurs de Tunis, \\ University of Tunis El Manar, \\ Tunis, Tunisia \\ Full list of author information \\ is available at the end of the \\ article
}

\begin{abstract}
Soil particle shape analysis was conducted on two calcareous sands from Dissa and Matmata in Tunisia and one silica sand from Jumunjin in Korea using an image analysis method. This technique uses complex Fourier shape descriptors and image analysis of sand grains SEM photographs to provide accurate quantification of particle morphology and texture. The Fourier descriptors, denoted "Signature Descriptors", provide measures of Elongation, Triangularity, Squareness, and Asymmetry and identify the overall shape of soil particles. A summary of higher-order descriptors provides textural information linked up to local roughness and texture characteristics. After analyzing the Fourier descriptors, elongation was found to be the major characteristics of the three sands, mainly for the Dissa and Matmata carbonate sands. In addition, the elongation signature descriptors for the Dissa and Matmata sands have very high values compared to those of Ras Alkhair (Saudi Arabia) and Dog's bay (Ireland) sands. Therefore, the Dissa and Matmata carbonate sands have higher angles of friction and higher critical state angle of friction than Ras Alkhair and Dog's bay sands. Furthermore, the Dissa and Matmata carbonate sands show higher roughness than Jumunjin's silica sand.
\end{abstract}

Keywords: Shape analysis, Fourier descriptor, Carbonate sand, Jumunjin sand, Dissa sand, Matmata sand

\section{Introduction}

In Civil engineering literature, the mechanical behavior of sands is related to their microcharacteristics and particle morphology. Moreover, the variation of packing ability, compression properties, yielding, and stiffness parameters are interpreted as a function of absolute particle size and variability of grading, as well as their particle micro-characteristics (e.g.: [2, 8, 9, 13, 23, 27, 29]).

According to Kandhal and Parker [18], Saeed et al. [25] and Meininger [20], the form, angularity, and texture of fine, and coarse aggregate particles used in hot-mix asphalt (HMA), hydraulic cement concrete, and unbound base and subbase layers influence their mutual interactions and interactions with any stabilizing agents (e.g., asphalt, cement, and lime) and are related to durability, workability, shear resistance, tensile strength, stiffness, fatigue response, optimum stabilizer content, and, ultimately, the performance of the pavement layer. Therefore, the fundamental measurements of aggregate shape characteristics are essential for the high-quality control

(c) The Author(s) 2020. This article is licensed under a Creative Commons Attribution 4.0 International License, which permits use, sharing, adaptation, distribution and reproduction in any medium or format, as long as you give appropriate credit to the original author(s) and the source, provide a link to the Creative Commons licence, and indicate if changes were made. The images or other third party material in this article are included in the article's Creative Commons licence, unless indicated otherwise in a credit line to the material. If material is not included in the article's Creative Commons licence and your intended use is not permitted by statutory regulation or exceeds the permitted use, you will need to obtain permission directly from the copyright holder. To view a copy of this licence, visit http://creativeco mmons.org/licenses/by/4.0/. 
of aggregates and the understanding of the influence of these characteristics on the behavior of pavement structural layers, cement concrete, etc.

Particle shape is generally assumed to consist of three different independent properties: Form, Angularity, and Roughness (Fig. 1). Particle form describes the general shape and is simply understood as its geometric form determined by the relative length of the particle intercepts along the three perpendicular axes corresponding to three orthogonal axes $\mathrm{X}, \mathrm{Y}$, and $\mathrm{Z}$. The particle angularity or roundness describes the relative sharpness of the angles on the surface. The particle roughness or surface texture describes the microscopic undulations on the particle surface. The skeletal particles of carbonate sands are varied and diverse in their size, shape, and ability to resist mechanical and chemical effects. According to , Brandes [6], Bui et al. [7], Cho et al. [9], Hassanlourad et al. [16], Miura et al. [22], Safinus et al. [26], and Siang et al. [28], calcareous sands are very angular and exist at a higher void ratio than silica sands. Moreover, the particles of carbonate sands vary in size and shape, hence producing well-graded distribution curves, whereas silica sands have generally a uniform grade.

The application of silica shape charts based on 2D plane images to determine the degree of shape for calcareous sand particles is, therefore, unrealistic and unreasonable [14].

Given the importance of shape analysis of objects and particles across a wide range of disciplines, many methods have been proposed in the literature. For example, Fourier descriptor analysis is an approach that has become much easier to implement as digital images and image analysis software $[5,10,12,21]$. The present work aimed to comprehend and identify the shape of two calcareous sands and one silica sand using the Fourier descriptor analysis.

James and Vallejo [17] defined roughness as the general shape and surface irregularity. They emphasized that it is an important characteristic that affects the mass behavior of the soil. According to Alshibli and Alsaleh [1], an increase in the surface roughness leads to an increase in the friction and dilatancy angles.

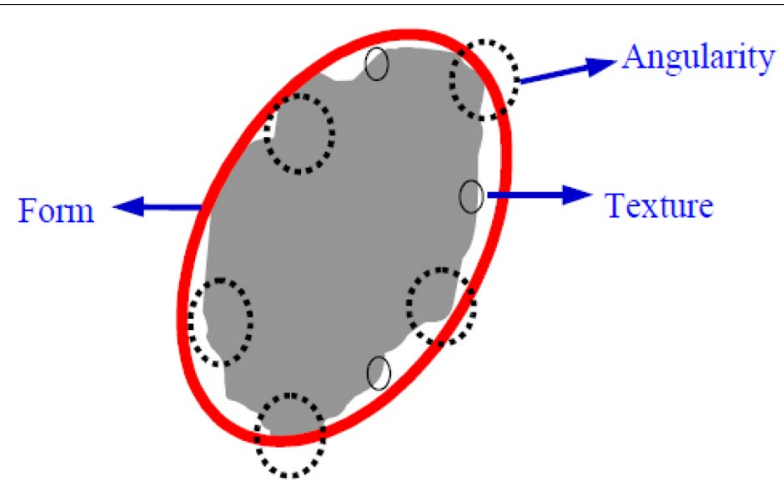

Fig. 1 Components of aggregate shape properties: form, angularity and texture (after Masad [19]) 


\section{Brief introduction to the $\mathbf{2} \mathbf{d}$ fourier approach}

Fourier Descriptors were first introduced by Ehrlich et al. [12] for particle shape characterization and were further applied by several authors to sand characterization $[5,10$, $21,29]$. These studies showed that the average normalized Fourier spectrum of the $2 \mathrm{D}$ contours (obtained by projection) of a population of sand particles could embody a relevant signature of the shape features of these particles. Specifically, the normalized Fourier spectrum of a $2 \mathrm{D}$ contour for a particle is denoted by a collection of numbers, also called Fourier descriptors:

$$
D_{n}=\frac{\sqrt{A_{n}^{2}+B_{n}^{2}}}{r_{0}}\left(0 \leq n \leq \frac{N}{2}\right)
$$

where the terms $A_{n}, B_{n}$, and $r_{0}$ can be obtained by Discrete Fourier Transform of the contour expressed in polar $(r, \theta)$ coordinates and discretized in $N$ points:

$$
\begin{aligned}
& A_{n}=\frac{1}{n} \sum_{i=1}^{N}\left[r_{i} \cos \left(i . \theta_{i}\right)\right] \\
& B_{n}=\frac{1}{N} \sum_{i=1}^{N}\left[r_{i} \sin \left(i . \theta_{i}\right)\right] \\
& r_{0}=\frac{1}{N} \sum_{i=1}^{N}\left[r_{i}\right]
\end{aligned}
$$

The normalization (division by $r_{0}$ ) ensures that mode $D_{0}$ (average particle radius) is equal to 1 , and a proper choice of the particle center ensures that mode $D_{1}$ (corresponding to some shift of the particle from its center) is equal to 0 . An example of Fourier Spectrum with $\mathrm{N} / 2=64$ is provided in Fig. $2 \mathrm{a}$.

This method has been widely used for the characterization of sand particle shapes since there is a direct correlation between the normalized Fourier spectrum $\left\{D_{n}\right\}$ and some intrinsic properties of the grains. It was indeed shown that mode $\mathrm{D}_{2}$ controls the particle elongation, modes $D_{3}$ to $D_{7}$ control the main irregularities of the overall particle shape, and modes $D_{n}$ for $n>7$ (which most often follow a linear decrease with $n$ in a $\log -\log$ frame and can thus be described using only a slope and an intercept) are good descriptors of the particle surface roughness.

\section{Implementation of image processing/analysis}

\section{Methodology}

Using an optical microscope, digital images of 200 times magnification of sand grains were taken. For quantitative comparison of shapes using the Fourier method, preprocessing of digital images was conducted. In order to analyze the shape of the sand particles using a digital image magnified by an optical microscope, information on the boundary surface of the sand particles must be extracted. First, a gray scale image is generated by removing color information of a digital image. By adjusting the brightness of the grayscale image, the boundary of the particle is made clear, and a binary image is 

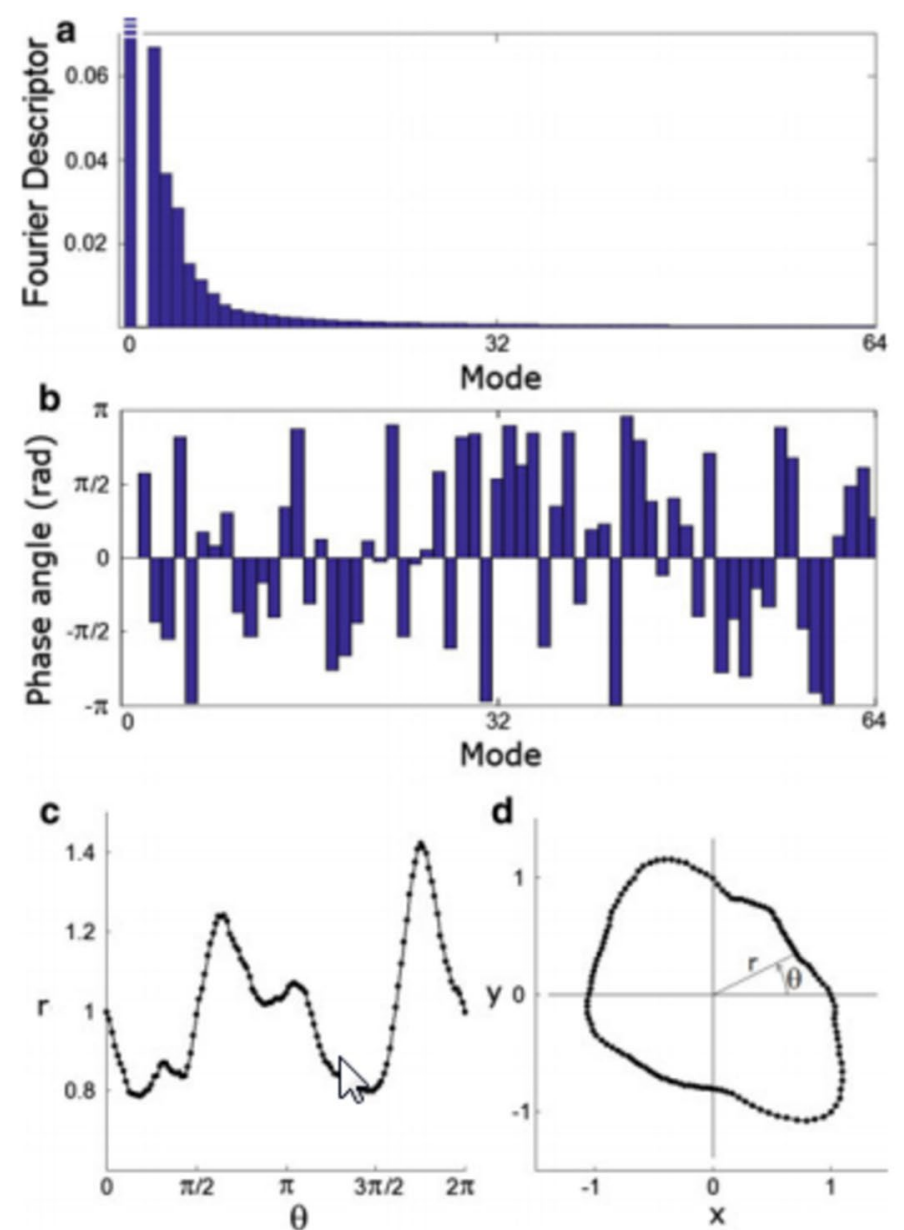

Fig. 2 a lllustrative discrete Fourier spectrum; $\mathbf{b}$ random sampling of phase angles; c corresponding $r(\theta)$ discrete signal; $\mathbf{d}$ particle contour in a Cartesian frame

created. Shape analysis is performed by extracting the boundary surface from the black and white image. The series of digital image processing were processed using in-house MATLAB code.

\section{Geometrical meaning of descriptors (Bowman et al. approach)}

The link between the descriptor values and the particle shape is illustrated in Figs. 3 and 4. The precise nature of this link must be established so that the values of the descriptors can be used for particle characterization. A geometrical interpretation of the spectra resulting from the Fourier analysis to derive roundness information for grains was proposed.

Diepenbroek et al. [11] proposed a geometrical interpretation of the spectra resulting from the Fourier analysis to derive roundness information about grains. By analyzing the harmonics resulting from a Fourier series analysis, Diepenbroek et al. proposed that the zeroth harmonic produces a circle with a diameter equal to the mean diameter of the grain outline. The second harmonic adds a component of elongation. The third harmonic adds a triangular component and the fourth adds a square component. In general, 

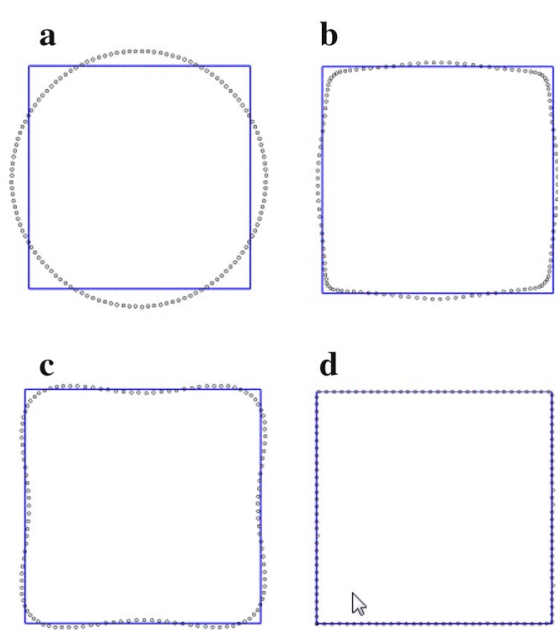

Fig. 3 The importance of high order Fourier descriptors in the reconstruction of a simple shape, a square: a $c^{B}(0)$ and $c^{B}(1)$ only; $\mathbf{b} c^{B}(0)+c^{B}(1)$ and $c^{B}(-8)$ to $c^{B}(-1)$ only; $\mathbf{c} c^{B}(0)$ to $c^{B}(6)$ and $c^{B}(-3)$ to $c^{B}(-1)$ only; $\mathbf{d}$ all 128 descriptors [17]

as K increases, higher frequency sinusoidal waves with increasing frequency and smaller magnitude are considered.

Bowman et al. [5] used six standard shapes to extract features of the Fourier descriptors, namely a circle, an ellipse, a rectangle, a square, an equilateral triangle, and an isosceles triangle. From the analysis of the standard shapes, particular features or signature descriptors were obtained.

Bowman et al. [5] used the following convention to index the Fourier descriptors: $\mathrm{c}^{\mathrm{B}}(0)$ gives the radius or the particle size, $c^{\mathrm{B}}(-1)$ gives the elongation, $c^{\mathrm{B}}(-2)$ gives a measure triangularity, $c^{\mathrm{B}}(-3)$ quantifies squareness, and $c^{\mathrm{B}}(+1)$ gives a measure of asymmetry or irregularity such that the regular shapes with the center of gravity equidistant from any corner have values of 0.00 . The second-order elongation and triangularity are given by respectively $\mathrm{c}^{\mathrm{B}}(+2)$ and $\mathrm{c}^{\mathrm{B}}(+3)$.

\section{Validation-application to ideal particles}

The six standard shapes considered by Bowman et al. [5] were used to validate the MATLAB implementation of this approach. The magnitude of the descriptors is related to particle geometry as illustrated in Fig. 4. As can be seen from the shapes presented in Fig. 4, elongation is quantified only for the ellipse, the rectangle, and the isosceles triangle. The triangularity descriptor is non-zero only for the triangle shapes. The triangularity is greater in magnitude for the equilateral and decreases with the increasing elongation of the triangle. The squareness descriptor has a maximum value for the square; however, it does have a non-zero value for the rectangle, the ellipse, and the isosceles triangle. The asymmetry is only non-zero for the isosceles triangle; all the other shapes are considered symmetric or regular. Secondary elongation describes the same shapes as elongation but with inferior coefficients. It has also been found that in a triangle with rough faces, the coefficient becomes non-zero. Similarly, the secondary triangularity has non-zero values for the triangles and the rough shapes. Based on these 


\begin{tabular}{|c|c|c|}
\hline Shape & $\begin{array}{c}\text { Coefficient } \\
(\mathrm{k})\end{array}$ & $\begin{array}{l}\text { Descriptor } \\
\text { (Bowman) }\end{array}$ \\
\hline \multirow{6}{*}{$\mathbf{a}$} & -1 & 0.0000 \\
\hline & 1 & 0.0000 \\
\hline & -2 & 0.0000 \\
\hline & 2 & 0.0000 \\
\hline & -3 & 0.0000 \\
\hline & 3 & 0.0000 \\
\hline \multirow[b]{6}{*}{ D } & -1 & 0.2607 \\
\hline & 1 & 0.0000 \\
\hline & -2 & 0.0000 \\
\hline & 2 & 0.0749 \\
\hline & -3 & 0.0137 \\
\hline & 3 & 0.0000 \\
\hline \multirow[b]{6}{*}{ c } & -1 & 0.2800 \\
\hline & 1 & 0.0000 \\
\hline & -2 & 0.0000 \\
\hline & 2 & 0.0814 \\
\hline & -3 & 0.0814 \\
\hline & 3 & 0.0000 \\
\hline \multirow{6}{*}{ d } & -1 & 0.0000 \\
\hline & 1 & 0.0000 \\
\hline & -2 & 0.0000 \\
\hline & 2 & 0.0000 \\
\hline & -3 & 0.1113 \\
\hline & 3 & 0.0000 \\
\hline & -1 & 0.2341 \\
\hline & 1 & 0.0346 \\
\hline & -2 & 0.2286 \\
\hline & 2 & 0.0467 \\
\hline \multirow{2}{*}{ e } & -3 & 0.0281 \\
\hline & 3 & 0.0496 \\
\hline \multirow{4}{*}{$\wedge$} & -1 & 0.0001 \\
\hline & 1 & 0.0001 \\
\hline & -2 & 0.2500 \\
\hline & 2 & 0.0001 \\
\hline \multirow{2}{*}{ f } & -3 & 0.0001 \\
\hline & 3 & 0.0625 \\
\hline
\end{tabular}

Fig. 4 General shapes used to investigate Fourier shape descriptors for morphological description: - 1 Elongation, -2 Triangularity, -3 Squareness, + I Asymmetry, + 2 s Order Elongation, + 3 Second Order Triangularity Bowman et al. [5]

results, Bowman et al. [5] proposed that the four signature descriptors $c^{\mathrm{B}}(-1), c^{\mathrm{B}}(-2)$, $c^{B}(-3)$, and $c^{B}(2)$ are enough to describe the particle morphology. Indeed, the rough 
shapes show a slight decrease in these descriptors and an increase in higher-order ones; although the signature morphology is not affected.

\section{Application: results and discussion}

\section{Application to real sand}

The Fourier shape descriptors method was used for the characterization of real soil particles considering three sands: The Jumunjin silica Sand (JSS), the Dissa calcareous sand (DCS), and the Matmata calcareous sand (MCS).

The JSS is silica sand from the region of Hyanghori, Jumunjin, in the South of Korea. It is composed of sub rounded to rounded grains of quartz origin.

The Dissa and Matmata sands are bioclastic calcareous sands from the Djebel Dahar in the South of Tunisia. The Jebel Dahar was formed during the withdrawal of the Tethys Ocean nearly 140 million years ago and the last marine deposits on the Dahar Plateau are characterized by thick shallow carbonates-marl marine sequences deposited in the Late Cretaceous [3]. The DCS and MCS have high CaCO3 content in the form of calcite and consist mainly of angular and platy grain shape. MCS contains some unbroken angular mollusk and foraminifera shells, many of which have intra-particle voids. These features result in fragile particles and high specific volumes. The particle size distributions for the tested sands are given in Fig. 5.

The particle size of these aggregates varies from 0.063 to $4 \mathrm{~mm}$. The evaluated aggregate particles passed $0.6 \mathrm{~mm}$ and were retained on a $0.3 \mathrm{~mm}$ sieve.

Samples of Dissa and Matmata calcareous sands as well as Jumunjin silica sand, were observed under a scanning electron microscope (Figs. 6, 7 and 8). It was found that JSS has higher roundness, quite more regular shapes, cleaner surfaces and smoother texture. The Dissa and Matmata Carbonate sands exhibit irregular shapes, many sharp corners, surface roughness, and the presence of calcareous sand dust

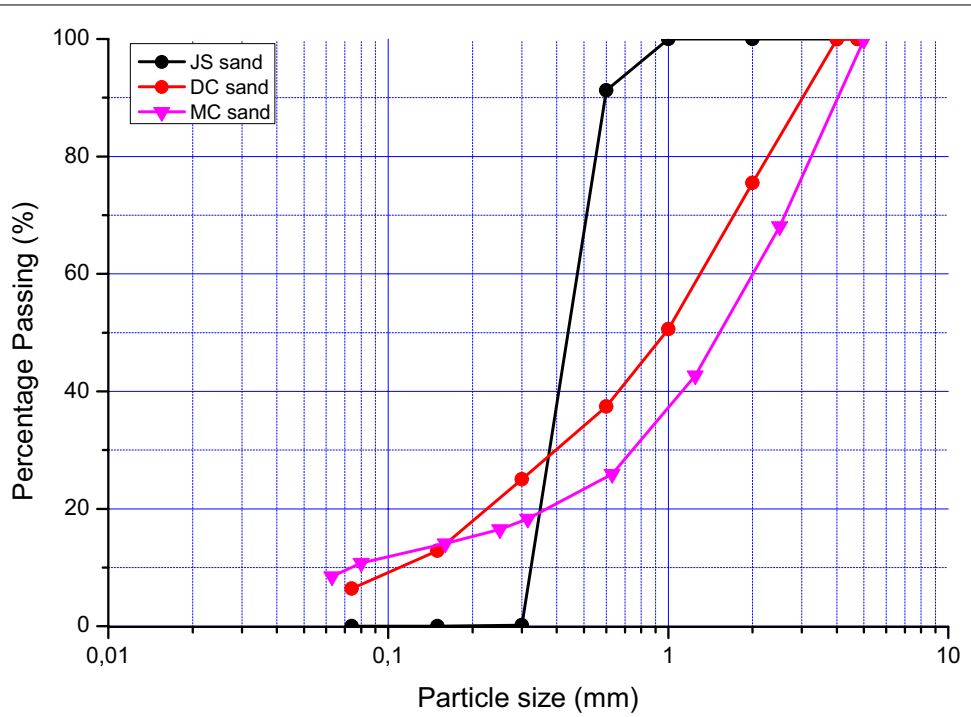

Fig. 5 Grain size distributions Curves of three sand samples: Jumunjin silica sand, Dissa calcareous sand and Matmata calcareous sand 


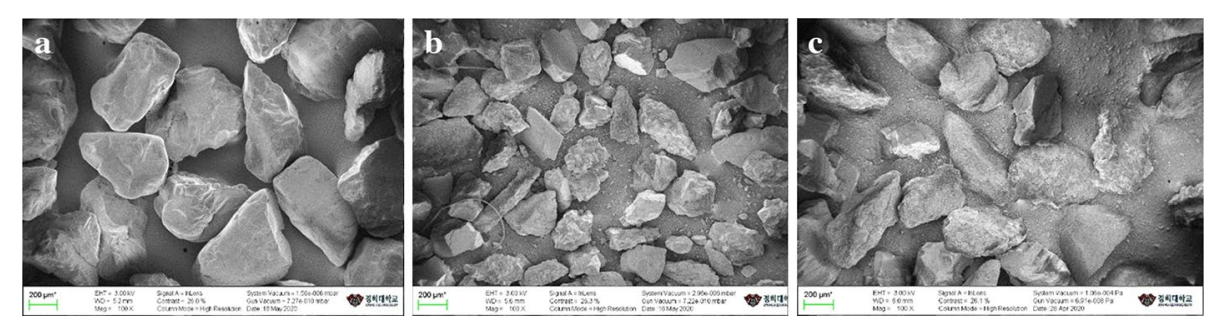

Fig. 6 The SEM images for test materials with size of $0.25-0.425 \mathrm{~mm}$ : a the Jumunjin silica Sand; $\mathbf{b}$ the Dissa Calcareous sand; $\mathbf{c}$ the Matmata calcareous sand

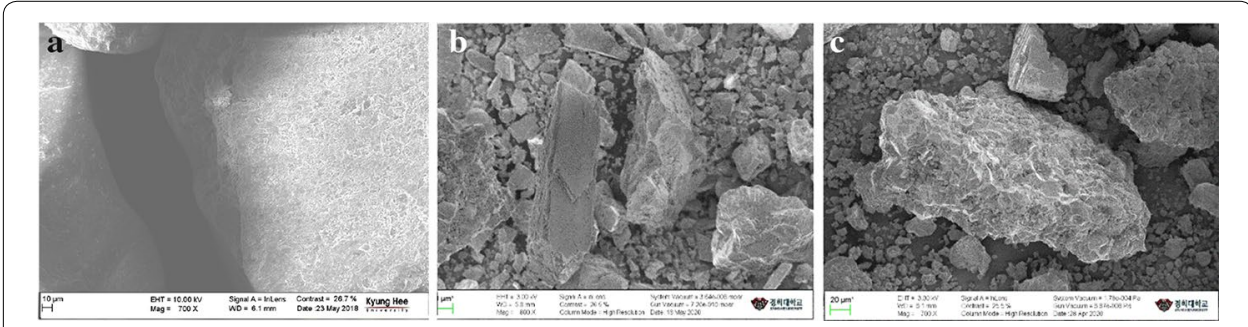

Fig. 7 The Scanning electron microscope (SEM) for test materials with size of 0.09-0.25 mm sand particle magnification: a the Jumunjin silica Sand; $\boldsymbol{b}$ the Dissa Calcareous sand; $\mathbf{c}$ the Matmata calcareous sand
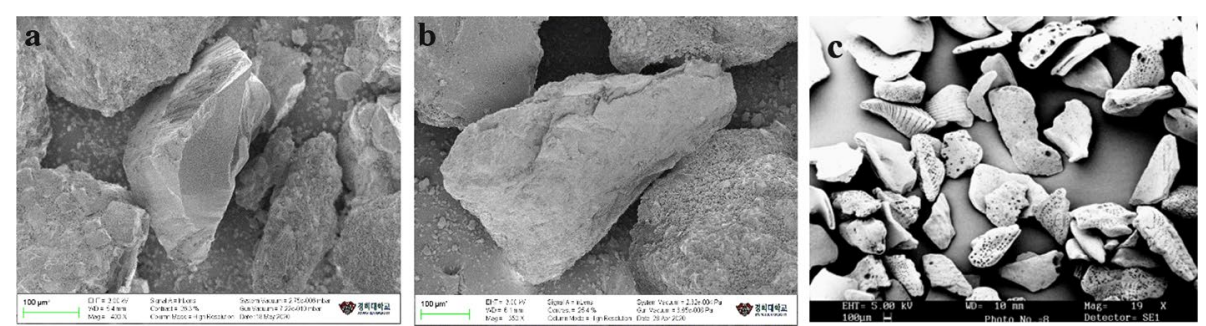

Fig. 8 The Scanning electron microscope (SEM) images of calcareous sands: a The Dissa Calcareous sand; b the Matmata calcareous sand; c Dog's Bay carbonate sand (SEM image from Bowman et al. [5])

around sand grains resulting from particle attrition. The DCS and MCS are more crushable and less stiff than the JSS.

The Dissa and Matmata Carbonate sands are quite similar in shape as Dog's Bay carbonate sand with sub-angular to angular particles (Fig. 8), However DCS and MCS are poor in skeletal grains and fragments of mollusk and have few interior voids.

Before performing the statistical evaluations, it is necessary to determine the number of particles profiles to be evaluated so that a statistically stable value can be obtained. Figure 9 presents the asymptotic analysis for DCS. It is found that 70 particles are enough to come up with a statistically meaningful value for the Asymmetry, Triangularity, and Elongation, while 80 particles are needed for Squareness. In the actual evaluations, 100 particles were evaluated for each sand. 


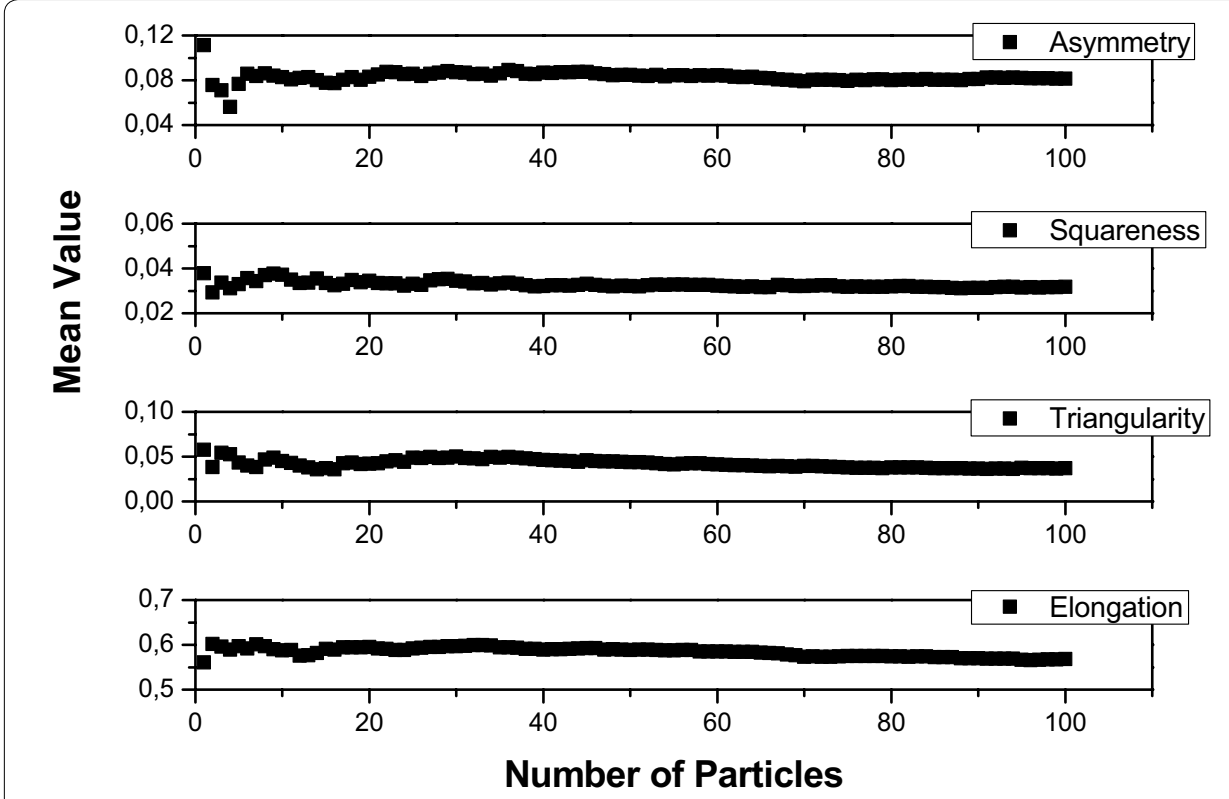

Fig. 9 Asymptotic analysis to determine required number of particle profiles

\section{Soil particle shape analysis results and discussion}

The shape analysis was carried out for the three sands. The average values of Fourier shape descriptors are illustrated in Figs. 10, 11, and 12. They present a relatively small value except for the Fourier descriptors ranging from -3 to +3 . Note that we used the same convention as Bowman et al. [5] to index our Fourier descriptors.

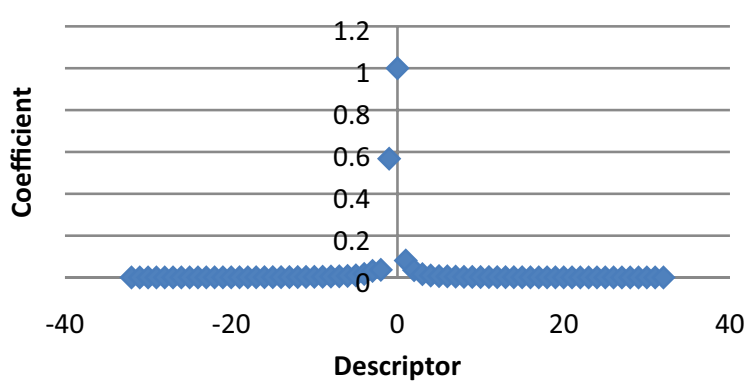

Fig. 10 Descriptor magnitude for Dissa calcareous sand

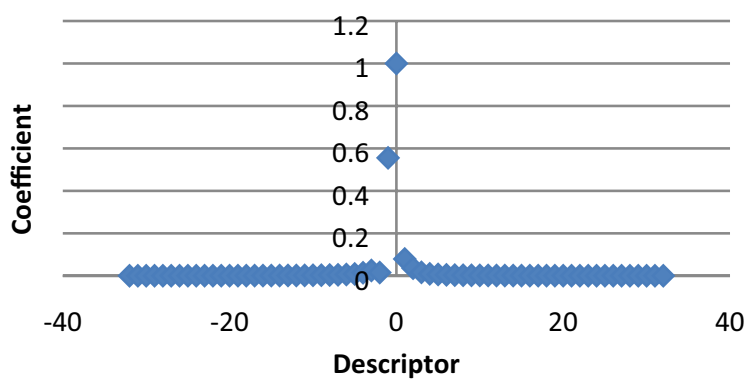

Fig. 11 Descriptor magnitude for Matmata calcareous sand 


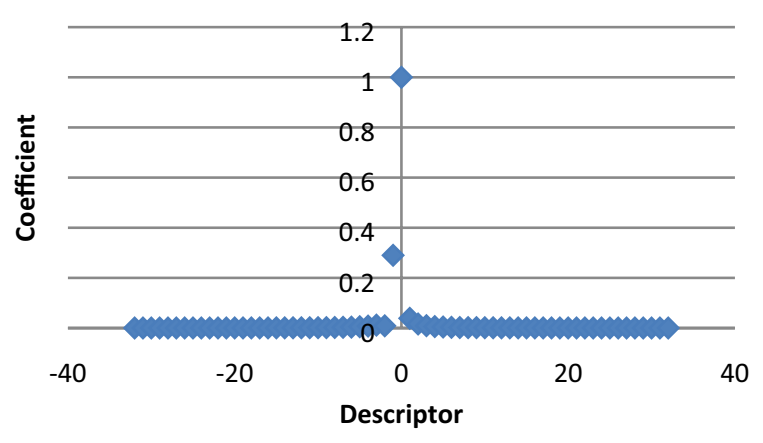

Fig. 12 Descriptor magnitude for Jumunjin silica sand

Table 1 General shapes used to investigate Fourier descriptors for morphological characterization, Mean values for the signature descriptors

\begin{tabular}{|c|c|c|c|c|c|}
\hline \multirow[t]{2}{*}{ Soil type } & \multirow{2}{*}{$\begin{array}{l}\text { Number } \\
\text { of particles }\end{array}$} & \multicolumn{4}{|c|}{ Mean values for the signature descriptors } \\
\hline & & $\begin{array}{l}-1 \\
\text { Elongation }\end{array}$ & $\begin{array}{l}-2 \\
\text { Triangularity }\end{array}$ & $\begin{array}{l}-3 \\
\text { Squareness }\end{array}$ & $\begin{array}{l}+1 \\
\text { Asymmetry }\end{array}$ \\
\hline DCS & 100 & 0.5722 & 0.0321 & 0.0304 & 0.0810 \\
\hline MCS & 100 & 0.5789 & 0.0130 & 0.0252 & 0.0777 \\
\hline JSS & 100 & 0.2901 & 0.0088 & 0.0116 & 0.0380 \\
\hline
\end{tabular}

Table 2 General shapes used to investigate Fourier descriptors for morphological characterization, Standard Deviation values for the signature descriptors

\begin{tabular}{lllll}
\hline Soil type & \multicolumn{4}{l}{ Standard deviation values for the signature descriptors } \\
\cline { 2 - 5 } & $\mathbf{- 1}$ & $\mathbf{- 2}$ & $\mathbf{- 3}$ & $\mathbf{+ 1}$ \\
& Elongation & Triangularity & Squareness & Asymmetry \\
\hline DCS & 0.0640 & 0.0260 & 0.0150 & 0.0412 \\
MCS & 0.0401 & 0.0082 & 0.0142 & 0.0371 \\
JSS & 0.0599 & 0.0057 & 0.0061 & 0.02164 \\
\hline
\end{tabular}

Table 3 General shapes used to investigate Fourier descriptors for morphological characterization, relative standard deviation values for the signature descriptors

\begin{tabular}{lllll}
\hline Soil type & \multicolumn{4}{l}{ Relative standard deviation values for the signature descriptors (\%) } \\
\cline { 2 - 5 } & $\mathbf{- 1}$ & $\mathbf{- 2}$ & $\mathbf{- 3}$ & $\mathbf{+ 1}$ \\
& Elongation & Triangularity & Squareness & Asymmetry \\
\hline DCS & 11.18 & 80.93 & 49.50 & 50.90 \\
MCS & 06.93 & 63.38 & 56.17 & 47.78 \\
JSS & 20.67 & 64.51 & 52.36 & 56.91 \\
\hline
\end{tabular}

Tables 1, 2 and 3 summarize the overall results of the study, giving the mean values of the signature descriptors for each considered soil type. The standard deviation for each signature descriptor was calculated to evaluate whether these mean values can be considered representative of the overall material. The descriptors values over a 
distance of $3 \sigma$ from the mean are not considered, knowing that the number of particles retained is always greater than 95 to 100 .

As illustrated in Tables 1,2 and 3), the elongation is the major characteristics of the three sands mainly for MCS and DCS as the signature descriptors for elongation have high values and the relative standard deviation is quite low. However, triangularity, squareness, and asymmetry have low values and the related standard deviations are very large compared to the mean descriptor values.

The elongation signature descriptors for the calcareous sands (DCS and MCS) have very high values (coeffs. $=0.5789,0.5722$ ) compared to the standard oval (coef. $=0.2601)$ and the standard rectangle (coeff. $=0.2680$ ).

The signature descriptors values for various carbonate sands: Dissa sand, Matmata sand, Ras Al Khair sand from Saudi Arabia, and Dog's bay sand from Ireland are illustrated in Table 4. For the various carbonate sands, the elongation signature descriptors have high values and the Asymmetry as well as the 2nd elongation signature descriptors have quite similar values.

According to Pottiary et al. [24] and Harkness and Zervos [15], the elongation form and the deviation of sand particles from that of a sphere lead to higher angles of friction and an increase in critical state strength. This increase in strength is accompanied by a reduction in the amount of rotation and an increase in interparticle sliding, a mechanism that in comparison requires more energy to be expended. Therefore, the Dissa and Matmata carbonate sands have higher angles of friction and higher critical state angle of friction than Ras Alkhair and Dog's bay sands.

As the large magnitude and low frequency in the Fourier representation are related to the shape of the boundary and angularity, while the small magnitude and high frequency are related to the roughness and surface texture. It can, therefore, be deduced that the carbonate sands show higher roughness than the Jumunjin silica Sand (Fig. 13) as the offset of the plot give a measure of the comparable roughness of each sand type, though the Dissa and Matmata carbonate sand show lower roughness than Dog's Bay carbonate sand. Besides the DCS indicates the lowest roughness decay to a smaller scale (Fig. 13) as the plot gradient gives a measure of the roughness decay to a smaller scale which may be related to the crystalline nature of the sand particle.

Table 4 Signature Descriptor coefficient for various calcareous sands: Dissa sand, Matmata sand and Ras Al Khair Sand

\begin{tabular}{|c|c|c|c|c|}
\hline \multirow[t]{2}{*}{ Descriptor } & \multicolumn{4}{|c|}{ Calcareous Sands } \\
\hline & DCS & MCS & Ras AI Khair Sand [4] & $\begin{array}{l}\text { Dog's bay } \\
\text { sand [5] }\end{array}$ \\
\hline-1 (Elongation) & 0.5722 & 0.5789 & 0.3721 & 0.2763 \\
\hline-2 (Triangularity) & 0.0321 & 0.0130 & 0.0071 & 0.0748 \\
\hline - 3 (Squareness) & 0.0304 & 0.0252 & 0.0195 & 0.0381 \\
\hline + 1 (Asymmetry) & 0.0810 & 0.0777 & 0.0700 & 0.0492 \\
\hline + 2 (2nd elongation) & 0.0346 & 0.0352 & 0.0274 & - \\
\hline
\end{tabular}




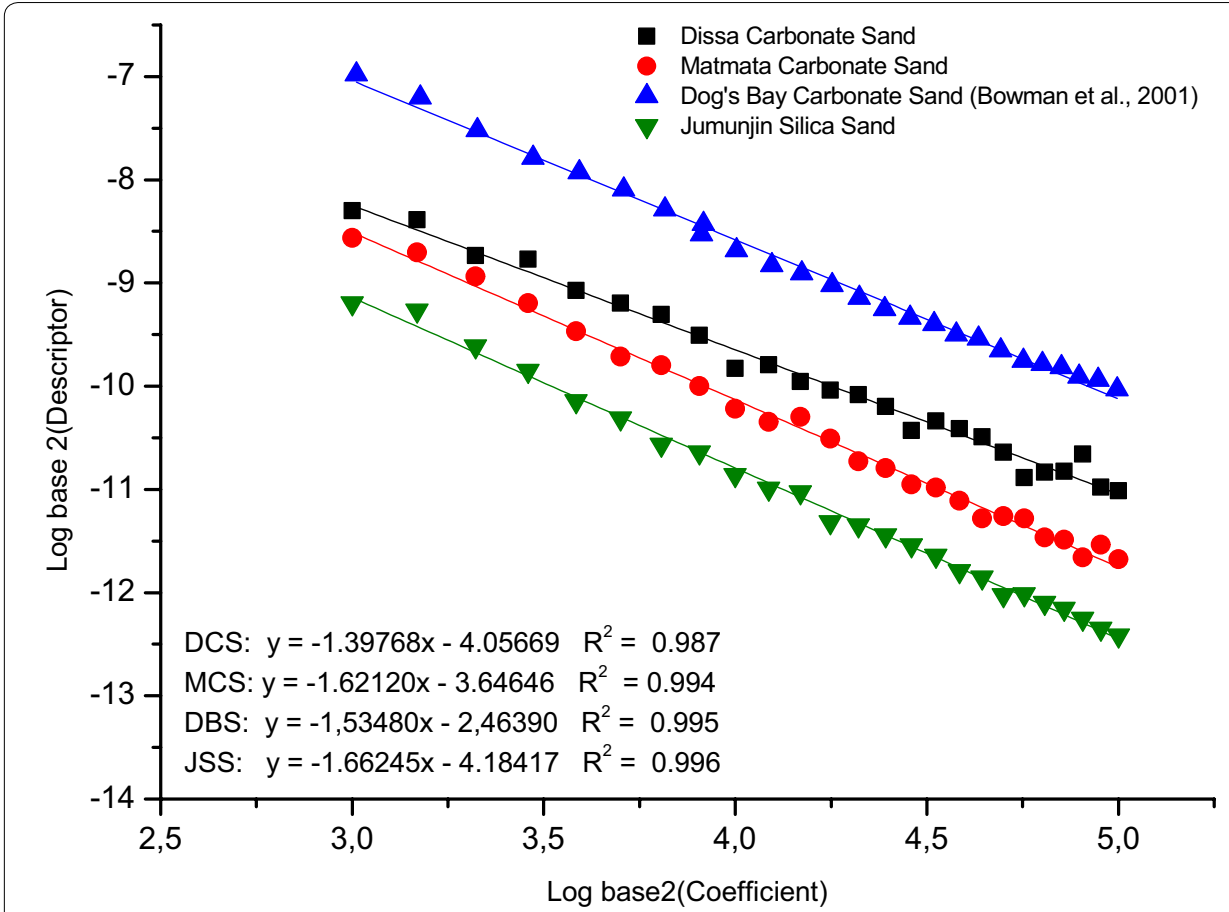

Fig. 13 Log/Log plot to base 2 of higher descriptors for Dissa sand, Matmata sand, Dog's Bay carbonate sand (from Bowman et al. [5]) and Jumunjin silica Sand

\section{Conclusion}

The main objective of this study was to understand the shape and the texture of the Dissa and Matmata carbonate sands as well as the Jumunjin silica sand. It was found that:

1 The elongation is the major characteristics of the three sands, mainly for MCS and DCS, as the signature descriptors for elongation have high values and the relative standard deviation is quite low.

2 The elongation signature descriptors for the Dissa and Matmata calcareous sands have very high values compared to those of Ras Al Khair and Dog's bay carbonate sands.

3 The Dissa and Matmata carbonate sands show higher roughness than the Jumunjin silica sand in relation to the micro- and macro-relief of the sand grain surface.

4 The Dissa and Matmata carbonate sands have higher angles of friction and higher critical state angle of friction than Ras Alkhair and Dog's bay sands.

5 The Matmata and Dissa grains shape as well as Ras Al Khair and Dog's bay carbonate grains shape is in the order of elongation and asymmetry.

6 The Dissa carbonate sands indicate the lowest roughness decay to a smaller scale than respectively Dog's bay carbonate sand, Matmata carbonate sand and Jumunjin silica sand. 


\section{Authors' contributions}

All authors contributed to the design and implementation of the idea. KT and JY-H performed the experiments. KT performed the implementation of image processing and analysis. JY-H coordinated between laboratories and ensured the electron microscope scans. LT performed the statistical analysis, wrote the manuscript and designed the figures. All authors discussed the results and contributed to the final manuscript. All authors read and approved the final manuscript.

\section{Competing interests}

The authors declare that they have no competing interests.

\section{Author details}

${ }^{1}$ LGC Civil Engineering Laboratory - Ecole Nationale d'Ingénieurs de Tunis, University of Tunis El Manar, Tunis, Tunisia. ${ }^{2}$ School of Urban and Civil Engineering, Hongik University, Mapo-gu, Seoul, Republic of Korea. ${ }^{3}$ Department of Civil Engineering, Kyung Hee University, Yongin 17104, Republic of Korea.

Received: 2 June 2020 Accepted: 6 August 2020

Published online: 08 October 2020

\section{References}

1. Alshibli KA, Alsaleh MI (2004) Characterizing surface roughness and shape of sands using digital microscopy. ASCE, J Comput Civil Eng, pp 36-45

2. AL Rousan TM (2004) Characterization of aggregate shape properties using a computer automated system. PhD, A\&M University-USA

3. Ben Hadj Ali M, Jédui Y, Ben Salem H, Memmi L (1985) La carte géologique de la Tunisie 1/500,000. Office Nationale des Mines, Service Géologique

4. Bonwhee K, Taesik K (2016) Particle shape analysis using Fourier descriptor analysis. J Kor Geo-Environ Soc 17(3):21-26

5. Bowman ET, Soga K, Drummond W (2001) Particle shape characterization using Fourier descriptor analysis. Geotechnique 51(6):545-554

6. Brandes HG (2011) Simple shear behavior of calcareous and quartz sands. Geotech Geol Eng 29(1):113-126. https:// doi.org/10.1007/s10706-010-9357-x

7. Bui MT, Clayton CRI, Priest JA (2007) Effects of particle shape on Gmax of geomaterials. In: Proceedings of 4th international conference on earthquake geotechnical engineering, No. 1536

8. Cavarretta I, Coop M, O'Sullivan C (2010) The influence of particle characteristics on the behaviour of coarse grained soils. Géotechnique 60(6):413-423

9. Cho GC, Dodds J, Santamarina JC (2006) Particle shape effects on packing density, stiffness, and strength: natural and crushed sands. J Geotech Geoenviron Eng. 132(5):591-602. https://doi.org/10.1061/ (ASCE) 1090-0241(2006)132:5(591)

10. Das N (2007) Modeling three-dimensional shape of sand grains using discrete element method. Ph.D. Thesis. University of South Florida. p. 149

11. Diepenbroek M, Bartholoma A, Ibbeken H (1992) How round is round? A new approach to the topic roundness by Fourier shape analysis. Sedimentology 39:411-422

12. Ehrlich R, Weinberg B (1970) An exact method for characterization of grain shape. J Sediment Petrol 40(1):205-212

13. Georgiannou VN (2011) Behavioural patterns of fine sands. Geotech Eng J SEAGS \& AGSSEA 42(4):26-41

14. Giang PHH, Van Impe P, Van Impe W, Menge P, Cnudde V, Haegeman W(2017) 3D particle shape of calcareous sand conducted by X-ray computed tomography. In: Proceedings of the 2 nd world congress on civil, structural, and environmental engineering (CSEE'17) Barcelona, Spain. https://doi.org/10.11159/icgre17.168

15. Harkness J, Zervos A (2019) Some effects of particle shape on the mechanical behaviour of granular materials. In: 8th international conference on discrete element methods

16. Hassanlourad M, Rasouli MR, Salehzadeh H (2014) A comparison between the undrained shear behavior of carbonate and quartz sands. Int J Civ Eng 12(4):338-350

17. James PH, Vallejo LE (1997) Fractal analysis of the roughness and size distribution of granular materials. Eng Geo (Amsterdam) 48:231-244

18. Kandhal PS, Parker FJ (1998) Aggregate tests related to asphalt concrete performance in pavements. National Cooperative Highway Research Program Report 405, Transportation Research Board, National Research Council, Washington, D.C.

19. Masad E (2001) Review of imaging techniques for characterizing the shape of aggregates used in asphalt mixes. Proceedings of the 9th Annual Symposium of the International Center for Aggregate Research (ICAR), Austin, TX

20. Meininger RC (1998) Aggregate test related to performance of portland cement concrete pavement. National Cooperative Highway Research Program Project 4-20A Final Report. Transportation Research Board, National Research Council, Washington, D.C.

21. Meloy TP (1977) Fast Fourier transform applied to shape analysis of particle silhouettes to obtain morphological data. Powder Technol 17:27-35

22. Miura K, Maeda K, Furukawa M, Toki S (1998) Mechanical characteristics of sands with different primary properties. Soils Found 38(4):159-172

23. Otsubo M, O'Sullivan C, Sim WW, Ibraim E (2015) Quantitative assessment of the influence of surface roughness on soil stiffness. Géotechnique 65(8):694-700

24. Pottiary M, Zervos A, Harkness J (2016) The Effect of particle elongation on the strength of granular materials. In: Proceedings 24th UK conference association for computational mechanics in engineering, vol. 11, pp. 31-34 
25. Saeed A, Hall J, Barker W (2001) Performance-related tests of aggregates for use in unbound pavement layers. National Cooperative Highway Research Program Report 453,Transportation Research Board, National Research Council, Washington, D.C.

26. Safinus S, Hossain MS, Randolph MF (2013) Comparison of stress-strain behaviour of carbonate and silicate sediments. In: Proceedings 18th international conference on soil mechanics and geotechnical engineering, pp. 267-270

27. Santamarina C, Cascante $G$ (1998) The effect of surface roughness on wave propagation parameters. Géotechnique 48(1):129-136. https://doi.org/10.1680/geot.1998.48.1.129

28. Siang AJLM, Wijeyesekera DC, Zainorabidin A, Bakar I (2012) The effects of particle morphology (shape and sizes) characteristics on its engineering behaviour and sustainable engineering performance of sand. Int J Integr Eng 4(3):27-37

29. Wang LB, Park JY, Mohammad LN (2003) Quantifications of morphology characteristics of aggregate from profile images. In: 82nd transportation research board annual meeting. Washington (USA)

30. Zhang X, Baudet BA, Yao T (2020) The influence of particle shape and mineralogy on the particle strength, breakage and compressibility. Geo-Engineering 11:1. https://doi.org/10.1186/s40703-020-0108-4

\section{Publisher's Note}

Springer Nature remains neutral with regard to jurisdictional claims in published maps and institutional affiliations.

\section{Submit your manuscript to a SpringerOpen ${ }^{\circ}$ journal and benefit from:}

- Convenient online submission

- Rigorous peer review

- Open access: articles freely available online

- High visibility within the field

- Retaining the copyright to your article

Submit your next manuscript at $\mathbf{s p r i n g e r o p e n . c o m ~}$ 